\section{New roadblock to HIV infection}

\section{By Michael J. Haas, Senior Writer}

The goal of developing an effective vaginal microbicide against HIV infection has eluded researchers ever since the first potential compound assessed, nonoxynol-9, proved to actually increase infection rates. In the Proceedings of the National Academy of Sciences, researchers led by Philippe Gallay at The Scripps Research Institute reported that syndecan-3, expressed on dendritic cells, presents a previously unknown route for HIV infection in vaginal mucosa. This finding may provide a strategy for developing another generation of microbicides that more completely address the process of HIV infection.

Development of microbicides has been slow in part because of a lack of validated animal models, markers for activity or true placebos. But development has also been slow because of the complex but incomplete picture of exactly how HIV infects vaginal mucosal cells.

First-generation microbicides did not specifically target HIV or HIV-host cell interactions, but instead took a broad-brush approach. Nonoxynol-9, the first such compound tested in clinical trials, caused inflammation that made vaginal mucosal cells more susceptible to HIV infection.

Second-generation microbicides, some of which are still in development, typically have been broad-spectrum, nonirritating polymers that were not specifically designed to target HIV but instead generically blocked the virus from interacting with host cells. But the lack of specificity has meant that most of these microbicides were likely to have limited effectiveness.

A few third-generation microbicides, some of which also remain in development, have taken a more focused approach by targeting the life cycle of the virus with non-nucleotide reverse transcriptase inhibitors (NNRTIs) or by targeting gp120 on the HIV envelope or the HIV coreceptor CC chemokine receptor 5 (CCR5). But as long as the full mechanism of HIV sexual transmission remains undetermined, it is unclear how effective any single strategy will be.

"No one knows the best way to develop microbicides to prevent HIV infection because no one knows the precise mechanism of sexual transmission," Zeda Rosenberg, CEO of The International Partnership for Microbicides, told SciBX.

The main question has been exactly how HIV interacts with dendritic cells (DCs).

When HIV is sexually transmitted, it is known that the virus lodges in the genital mucosa and is taken up by DCs. From there, HIV hijacks the DCs, which transport the virus to the lymph nodes and transfer HIV to T cells. What hasn't been known is how many types of DC receptors are hijacked by the virus.

Most studies of HIV-DC receptor interactions have focused on gp120, an essential component in binding the virus to host cells. But more recent studies of HIV particles suggested the involvement of a DC receptor not observed in the gp120 experiments.

The PNAS paper showed that syndecan-3 (SDC3) is highly expressed on immature DCs in epithelial tissue and serves as an HIV-1 attachment receptor that mediates virus transmission and infection by binding to gp120 on the virus envelope. ${ }^{1}$

The results also suggest that SDC3 binding protects HIV from degradation and preserves its infectivity, thereby helping DCs pass the infection to $\mathrm{T}$ cells.

Additionally, the researchers found that HIV-SDC3 binding proceeds independently of gp 120 binding to dendritic cell-specific ICAM-3-grabbing nonintegrin (DC-SIGN; CD209). DC-SIGN is a C-type lectin receptor already known to bind HIV. Although blocking only SDC3 partially inhibited HIV transmission, the researchers showed that blocking both targets completely prevented DCs from capturing the virus.

The implication of the in vitro studies is that effective microbicides should block interactions of gp 120 with both SDC3 and DC-SIGN.

"This is a high-quality paper, a definitive work," Mark Krystal, director of virology drug discovery at Bristol-Myers Squibb Co., told SciBX. "It is a seminal finding-not necessarily 'the' seminal finding, since it follows on the work on DC-SIGN. But it is another, essential piece of the puzzle. It is important because vaccines have not been as successful as expected, which puts more emphasis on preventives like microbicides."

Melissa Robbiani, director of biomedical HIV research at the Population Council's Center for Biomedical Research, agreed. "The results underscore the need for either a single, broad-acting microbicidal agent to block the various molecules that interact with HIV, or a combined strategy of targeting the various HIV receptors with several compounds," she said. "It is a promising development."

"This could have substantial implications for microbicide development," said Salim Abdool Karim, director of the Centre for the AIDS Programme of Research in South Africa and vice chancellor of research at the University of KwaZulu-Natal. "Since dendritic cells are most likely key targets for initial infection in the genital tract, blocking a combination of DC-SIGN and syndecan-3 could provide a useful strategy to block HIV infection in the form of a microbicide."

\section{Broad strokes or pointilism?}

HIV microbicide development has faced serious obstacles from its beginnings in the late 1990s.

The problems with nonoxynol-9, a detergent that disrupts virus envelopes or bacterial membranes, became apparent in a Phase II/III trial run by Family Health International, which showed increased HIV transmission in the treatment group. ${ }^{2}$ A later Phase II/III trial showed that the compound disrupted host cell membranes, causing inflammation that made the vaginal mucosa more susceptible to infection. ${ }^{3}$ 
Table 1. Microbicides for HIV. Selected microbicides to prevent HIV infection.

\begin{tabular}{|c|c|c|c|c|}
\hline Company/institution & Compound & Description & $\begin{array}{l}\text { Microbicide type/ } \\
\text { mechanism of action }\end{array}$ & Status \\
\hline $\mathrm{FHI}^{\mathrm{A}}$ & Nonoxynol-9 & Ionic detergent & $\begin{array}{l}\text { Disrupts viral envelopes, cell } \\
\text { membranes }\end{array}$ & $\begin{array}{l}\text { Failed Phase II/III trial in } \\
1998\end{array}$ \\
\hline CONRAD $^{\mathrm{B}} / \mathrm{FHI}$ & UsherCell & Cellulose sulfate gel & Broad-spectrum polymer & Phase III halted in Jan. 2007 \\
\hline CONRAD & Savvy glyminox & Unknown & Broad-spectrum polymer & Phase III halted in Sept. 2006 \\
\hline Population Council & Carraguard & Carrageenan-derived gel & $\begin{array}{l}\text { Broad-spectrum ionic } \\
\text { polymer }\end{array}$ & $\begin{array}{l}\text { Completed Phase III in } \\
\text { March 2007; results expected } \\
\text { early } 2008\end{array}$ \\
\hline $\begin{array}{l}\text { Gilead Sciences Inc. } \\
\text { (NASDAQ:GILD)/IPM } / \\
\text { CONRAD }\end{array}$ & $\begin{array}{l}\text { Viread tenofovir disoproxil } \\
\text { fumarate }\end{array}$ & $\mathrm{ARV}^{\mathrm{D}} 1 \%$ gel & $\mathrm{NNRTI}^{\mathrm{E}}$ targeting HIV & Phase II \\
\hline CONRAD & UC-781 & ARV carbomer gel & NNRTI targeting HIV & Phase I \\
\hline IPM & Dapivirine (TMC120) & ARV & NNRTI targeting HIV & $\begin{array}{l}\text { Phase I; to start Phase II/III } \\
\text { in late } 2009\end{array}$ \\
\hline $\begin{array}{l}\text { Indevus Pharmaceuticals Inc. } \\
\text { (NASDAQ:IDEV) }\end{array}$ & PRO2000 & $\begin{array}{l}\text { Naphthalene sulfonate } \\
\text { polymer gel }\end{array}$ & Binds HIV gp120 & Phase III \\
\hline $\begin{array}{l}\text { StarPharma Holdings Ltd. } \\
\text { (ASX:SPL; Pink:SPHRY) }\end{array}$ & VivaGel & Dendrimer SPL7013 & Binds HIV gp120 & $\begin{array}{l}\text { Phase I for prevention of } \\
\text { HIV and other sexually } \\
\text { transmitted diseases }\end{array}$ \\
\hline IPM & BMS793 & ARV & Binds HIV gp120 & Preclinical \\
\hline \multicolumn{5}{|l|}{ Combinations: } \\
\hline ReProtect Inc./Indevus & BufferGel/PRO2000 gel & $\begin{array}{l}\text { Nonsulfated polymer } \\
\text { gel/naphthalene sulfonate } \\
\text { polymer gel }\end{array}$ & $\begin{array}{l}\text { Broad-spectrum acidifying } \\
\text { polymer/binds HIV gp120 }\end{array}$ & $\begin{array}{l}\text { To complete Phase II/IIb in } \\
\text { the third quarter of } 2008\end{array}$ \\
\hline Population Council & $\begin{array}{l}\text { PC-815 (Carraguard plus } \\
\text { MIV-150) }\end{array}$ & $\begin{array}{l}\text { Carrageenan-derived } \\
\text { gel/ARV }\end{array}$ & $\begin{array}{l}\text { Broad-spectrum ionic } \\
\text { polymer/NNRTI targeting } \\
\text { HIV }\end{array}$ & $\begin{array}{l}\text { Preclinical; to start Phase I } \\
\text { in } 2008\end{array}$ \\
\hline
\end{tabular}

${ }^{A} F H I$, Family Health International (Research Triangle Park, N.C.). ${ }^{B}$ CONRAD, Contraceptive Research and Development Organization (Arlington, Va.). ${ }^{C} I P M$, International Partnership for Microbicides (Silver Spring, Md.). ${ }^{\circ} \mathrm{ARV}$, antiretroviral. ENNRTI, non-nucleoside reverse transcriptase inhibitor.

Since then, at least two other broad-spectrum polymer microbicides-Savvy glyminox gel and UsherCell gel-have failed in clinical trials, though for less alarming reasons (see Table 1, "Microbicides for HIV").

At least three other broad-spectrum polymer microbicides are in the clinic or have recently completed clinical trials.

Indevus Pharmaceuticals Inc. has its PRO2000 gel in two Phase III trials to prevent HIV infection; the trials are scheduled to finish in mid2008 and 2009.

Indevus also has PRO2000 in a Phase II/IIb trial with ReProtect Inc.'s BufferGel to prevent HIV, with completion expected in the third quarter of 2008 .

Last March, the Population Council completed a Phase III trial of Carraguard to prevent HIV infection and expects to present the results in February.

The Population Council also has PC-815-Carraguard plus MIV150-in preclinical development, with Phase I trials planned for this year, according to Naomi Rutenberg, director of the HIV and AIDS program at the Population Council. MIV-150 is an NNRTI developed in a joint venture between Medivir AB and Chiron Corp., which is now owned by Novartis AG.

Because their action is not specific against HIV, some of these broad-spectrum agents can prevent other viral STDs as well. But that same nonspecificity means that they might not be $100 \%$ effective in preventing HIV infection. According to a recent review, most trials of broad-spectrum HIV microbicides are designed with a target efficacy of about $50 \%$-although target efficacy in some trials is as low as $30 \%{ }^{4}$

Several antiretrovirals (ARVs) are in clinical trials as third-generation microbicides to prevent HIV infection. A potential drawback to ARV microbicides is the potential for the virus to develop resistance-which broad-spectrum microbicides are less likely to promote.

The International Partnership for Microbicides has royalty-free licenses to develop two ARVs for use as microbicides in resource-poor countries.

\section{Blocking strategies}

Thus, a key question for new microbicide development is how best to completely block gp120-receptor interactions.

With that goal in mind, Scripps' Gallay and colleagues are developing anti-SDC3 antibodies and fusion proteins. Gallay doesn't expect the compounds to cause vaginal inflammation because they are derived from naturally occurring host proteins.

Gallay, associate professor of immunology at Scripps and spokes- 
person for the research team, told SciBX that he expects to complete in vitro optimization of the antibodies and fusion proteins and begin in vivo studies in macaques by July 2008.

"The macaque studies will be very important to show proof of concept: that by blocking syndecan-3, we can block HIV transmission in vaginal cells," he said.

Gallay also said he expects that an SDC3-based microbicide would be used in combination with other microbicides targeting other receptors and/or gp120.

Gallay and colleagues have not patented or licensed their work, but will reconsider their options after completing the in vivo studies.

According to Jan van de Winkel, executive VP and CSO at Genmab A/S, antibodies are effective at blocking HIV uptake by cells, but the nature of HIV infection adds a twist to an anti-SDC3 antibody strategy.

"Targeting normal cells with antibodies is an advantage against HIV because it reduces the chances for the virus to develop resistance," van de Winkel told SciBX. "But an important consideration for using antibodies this way is that you don't want to deplete immune cells; you just want to block a response."

Genmab has zanolimumab (HuMax-CD4), a human mAb against CD4, in preclinical development to prevent or slow HIV infection. The company also has an anti-CD4 UniBody-which van de Winkel described as a "half-molecule" designed to silence a response without killing the cell-in preclinical development for HIV.

"We find the syndecan-3 work interesting, but we are not in a position to pursue it," van de Winkel said. "Cancer is our primary focus, so right now we are not inherently motivated to look at HIV beyond CD4."

Another open question is whether SDC3-derived fusion proteins would make effective microbicides.

"Even if the fusion protein binds gp120, it's possible that other parts of the HIV envelope could bind to other receptors," said Robbiani. "You have to take care not to assume that binding gp120 means that HIV is blocked."

"For instance, HIV bound by a fusion protein might be recognized as a foreign particle and still be taken up by DCs," she said. "HIV could exploit that as a pathway to infection."

\section{Mimicking syndecan}

Those caveats notwithstanding, the PNAS paper provides some mechanistic rationale for a couple of biotechs currently developing microbicides to prevent HIV transmission.

One is Starpharma Holdings Ltd., which is running a Phase I trial of its VivaGel microbicide. The product's active component, SPL7013, is a dendrimer that targets gp120.

"SPL7013 is thought to bind gp120, thus blocking the ability of gp120 to interact with receptors on T cells and DCs," said Jeremy Paull, VP of development and regulatory affairs at Starpharma. "The evidence for SPL7013 binding to gp120 is very strong and includes a number of different assays that are used to elucidate the mechanism of antiviral drugs on HIV."

He added: "We would hypothesize that VivaGel prevents binding of gp120 to syndecan-3 and other known specific HIV-1 receptors, such as DC-SIGN, on immune cells."
With the evidence in the paper, Paull said, "our confidence in the validity of the proposed mechanism of action for VivaGel is duly strengthened."

Starpharma expects to complete the Phase I trial of VivaGel in August 2008. The company also has the microbicide in Phase I testing for genital herpes and other sexually transmitted viral infections.

Indevus Pharmaceuticals Inc. also thinks that the PNAS paper helps explain the mechanism of the company's PRO2000 gel, a naphthalene sulfonate polymer.

Based on the results reported in PNAS, Al Profy, VP of preclinical development at Indevus, said it's likely PRO2000 gel prevents HIV from binding SDC3. "PRO2000 seems to inhibit interactions involving heparan sulfate proteoglycans," he said.

SDC3 is one of several heparan sulfate proteoglycans (HSPGs) found in human cells. HSPGs have been shown to bind several other viruses and bacteria, according to Gallay.

"For example, PRO2000 seems to prevent herpes simplex virus infection by binding to the viral glycoprotein $B$, preventing its interaction with host cell proteoglycans," Profy said. "In the case of HIV, the mechanism is believed to involve binding to the positively charged V3 region of gp 120 . Thus it might block syndecan-3 from binding to HIV.'

As further evidence that the microbicide blocks SDC3, Profy noted that "some studies have shown that PRO2000 prevents infected DCs from in trans infection of T cells."

He added: "It's possible that PRO2000 and other sulfated or sulfonated polymers act by mimicking cell-surface sulfated polysaccharides" such as SDC3 and others.

"The field needs new drug candidates with new mechanisms of action," Profy told SciBX. "Our strategy and the large-scale clinical trials of PRO2000 are not affected by this paper. But if an academic institution wanted to test PRO2000 on syndecan-3, we would be willing to provide PRO2000 to them - with the appropriate property transfer agreement."

\section{REFERENCES}

1. de Witte, L. et al. Proc. Natl. Acad. Sci. USA; published online Nov. 26 2007; doi:10.1073/pnas.0703747104

Contact: Philippe Gallay, Department of Immunology, The Scripps Research Institute, La Jolla, Calif. e-mail: gallay@scripps.edu

2. Roddy, R.E. et al. N. Engl. J. Med. 339, 504-510 (1998)

3. van Damme, L. et al. Lancet 360, 971-977 (2002)

4. Abdool Karim, S.S. in HIV Sequence Compendium 2005 (eds. Leitner, T. et al.) 33-40 (Los Alamos National Laboratory, Los Alamos, N.M., 2005)

\section{COMPANIES AND RESEARCH INSTITUTIONS MENTIONED}

Bristol-Myers Squibb Co. (NYSE:BMY), New York, N.Y. Centre for the AIDS Programme of Research in South Africa, Congella, South Africa

Chiron Corp., Emeryville, Calif.

Family Health International, Research Triangle Park, N.C. Genmab A/S (CSE:GEN), Copenhagen, Denmark Indevus Pharmaceuticals Inc. (NASDAQ:IDEV), Lexington, Mass.

The International Partnership for Microbicides, Silver Spring, Md.

Medivir AB (SSE:MVIR B), Huddinge, Sweden

Novartis AG (NYSE:NVS; SWX:NOVN), Basel, Switzerland

Population Council's Center for Biomedical Research, New York, N.Y.

ReProtect Inc., Baltimore, Md.

The Scripps Research Institute, La Jolla, Calif.

Starpharma Holdings Ltd. (ASX:SPL; Pink:SPHRY), Melbourne, Australia University of KwaZulu-Natal, Durban, South Africa 